\title{
Evaluating the Effect of Different Base Temperatures to Calculate Degree-Days
}

\author{
Xabat OREGI ${ }^{1}$, Carlos JIMENEZ-BESCOS ${ }^{2 *}$ \\ ${ }^{1}$ CAVIAR Research Group, Department of Architecture, University of the Basque Country \\ (UPV/EHU), Spain \\ ${ }^{2}$ Architecture, Energy and Environment Research Group, University of Nottingham, United Kingdom
}

\begin{abstract}
Degree-days are used as a forecasting tool to predict energy demand and for normalizing energy consumption to be able to compare between different properties across different years. The base temperature is the main aspect to accurately calculate degree-days. The aim of this study was to evaluate the effect of different base temperatures and their impact on the correlation between energy consumption and degree-days. The base temperature was selected as the standard $15^{\circ} \mathrm{C}$ for the region, the balance temperature calculated with dynamic building simulations and the thermostat temperature setting as collected by questionnaires. The methodology followed is based on the analysis of 20 properties located in the cities of Bilbao, San Sebastian and Vitoria in northern Spain. The properties are a combination of flats and houses, from different construction periods, tenancies, occupancy and sizes. This study had highlighted the effect and impact of selecting different base temperatures for the calculation of degree-days and the correlation between energy consumption and degree-days. While the use of the balance temperature as base temperature could generate very good correlation, they were not so dissimilar from using the standard $15^{\circ} \mathrm{C}$ base temperature to justify the amount of extra work required to generate the balance temperature. The use of the thermostat setting as an indication of the base temperature was not as reliable as the other base temperature methods in generating a good correlation to explain the energy consumption on the 20 properties investigated in this study.
\end{abstract}

Keywords - Balance temperature; base temperature; degree-day; energy consumption; thermostat

\section{INTRODUCTION}

Degree-days were created originally in the agricultural field but it is currently used as a forecasting tool to predict energy demand [1], and for normalizing energy consumption for easy comparison between different years for the assessment of retrofitting interventions [2]. The concept and calculation of degree-days has been well documented in the literature [3], [4]. The use of degree-days can provide a straightforward way to assess the impact of a warm or hard winter on the energy consumption to allow comparisons over different years. According to Mitchells [5], degree-days can be used as well to predict the energy demand for communities. The influence of weather variability on the demand of domestic energy can be assess by the use of degree days [6].

\footnotetext{
* Corresponding author.

E-mail address: carlos.jimenez-bescos@nottingham.ac.uk 
As highlighted by Bhatnagar et al. [7], degree days are highly used as indicators for heating and cooling loads and further more for ASHRAE climate zone classifications. While De Rosa et al. [8] referred to the use of degree days as a versatile indicator to assess energy performance.

One of the main aspects on the calculation of degree-days is the base temperature [9]. If the base temperature has been calculated correctly, then the correlation between energy consumption and degree-days will be a straight line [10]. Several methodologies have been developed across the year to calculate the base temperature, giving the impact on the degreedays calculations [11]. The base temperature can be used based on the heat balance point of the building at which no heating will be required, in the case of the northern region of Spain as $15^{\circ} \mathrm{C}$ [12]. Furthermore, it can be calculated by the energy signature methodology presented in the literature [13] with the main limitation of the need of high-resolution data to perform an accurate calculation. As presented by Jimenez-Bescos [14], degree-days can be calculated based on the monitor internal temperature of the property using Internet of Things sensors to provide a more accurate assessment.

Regardless of the taken standard value for the base temperature, the reality is that this can oscillate from the standard value [15]. As a consequence, selecting the wrong value for the base temperature will generate an error in the calculation of the degree-days [16]. The relationship between the degree day and simulation energy use was explore by D'Amico [17], showing the importance of the climate set used in the simulation.

As presented in this introduction, degree days is highly used to assess building energy performance and the precision of the assessment is influenced by the degree day base temperature. The gap in knowledge of this study is the assessment of the impact of degreeday base temperatures and its effect on energy use by means of correlation between energy consumption and degree-days. The correlation between energy consumption and degree-days is very important to be used as energy use indicators.

The aim of this study was to evaluate the effect of different base temperatures and their impact on the correlation between energy consumption and degree-days. The base temperature was selected as the standard 15 degree centigrade for the region [12], the balance temperature calculated with dynamic building simulations and the thermostat temperature setting as collected by questionnaires [18].

\section{Methodology}

The methodology followed in this paper is based on the analysis of 20 properties located in the cities of Bilbao, San Sebastian and Vitoria in northern Spain. The properties are a combination of flats and houses, from different construction periods, tenancies, occupancy and sizes. Details of the properties were presented by the authors in [18] containing all the specific parameters regarding the properties.

For each property, bills were collected at bimonthly intervals for a whole year, form July 2012 to June 2013. The bills relate to gas natural for the use of space heating and domestic hot water. Furthermore, the thermostat setting for each property was collected by a questionnaire, as presented in Jimenez-Bescos \& Oregi [18], and this setting will be used as the thermostat temperature.

According to the Institute for the Diversification and Saving of Energy [12] the base temperature for the calculation of degree-days in the region of the study should be 15 degrees centigrade. 
The balance temperature was calculated individually for each property and for each month of the study. The balance temperature is the temperature at which no heating is required and it is calculated based on the intersection of total heat loss, fabric and ventilation, and total gains, plotted on a graph showing heat losses and gains versus external energy for each month and each property as presented in Fig. 1.

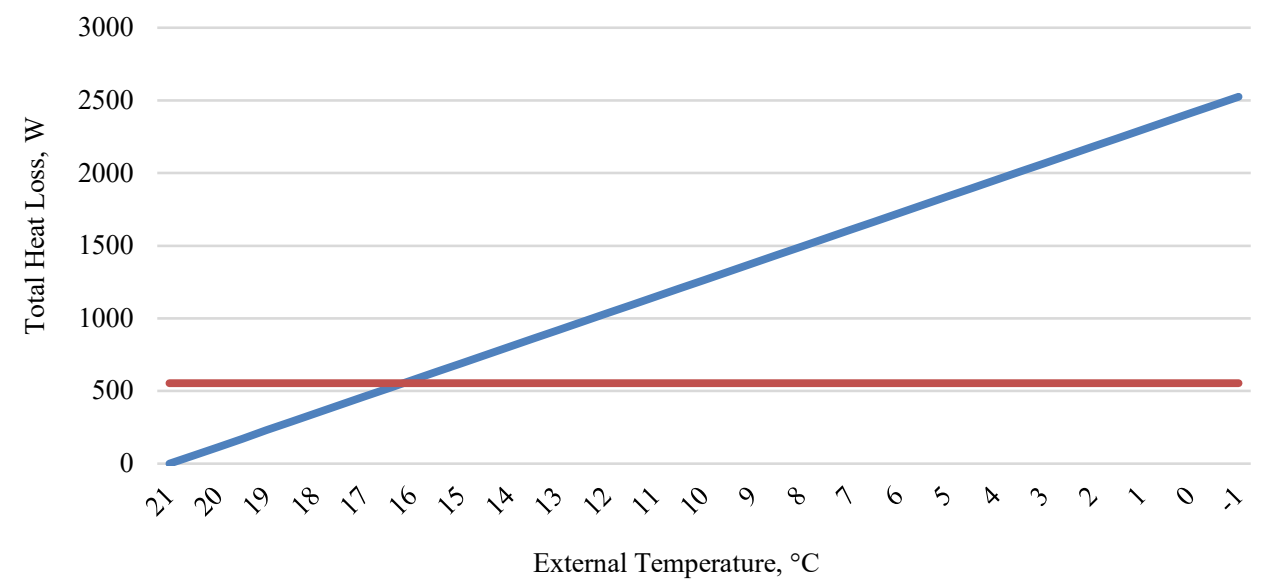

Fig. 1. Calculation of balance temperature for building 7 in January 2013.

The total heat loss contained the fabric and ventilation losses in accordance to the external temperature, being greater at lower external temperatures. While the total heat gains were calculated from the internal gains and solar gains calculated through dynamic building simulation in Design Builder [19] and they were accounting for the monthly variability of gains. The balance temperature was monthly collected for each property as shown in Fig. 1 for the calculation of degree-days.

Weather data was collected form Weather Underground [20] for the three locations in this study and daily average were employed for the calculation of degree-days.

Degree-days were generated on a daily basis from July 2012 to June 2013, as the base temperature minus the average external daily temperature, considering only positive values.

Three base temperatures were tested in this research:

- Thermostat temperature as collected form questionnaire [18];

- 15 degree centigrade in accordance to IDAE [12];

- The balance temperature collected monthly for each property.

As explained in the introduction, degree-days are used to normalized energy consumption and in an ideal scenario a correlation between energy consumption and degree-days should have a coefficient of determination, $R^{2}$, of value 1 , meaning how much the energy consumption of the property can be explained by the degree-days [21]. The coefficient of determination, $R^{2}$, will be changing between the values of 0 and 1 , representing a strong correlation the closer to one and on the opposite, no significant between variable the closer to zero. According to Collis and Hussey [22], a cause effect implication cannot be implied just by a strong correlation value of the coefficient of determination.

In this paper, as the degree-days are calculated based on three different base temperatures, the coefficient of determination, $R^{2}$, is to compare the correlation according to the three 
different approaches to calculate degree-days and its fitness to explain the energy consumption.

\section{RESUlts}

Table 1 shows an example of the process followed for each building, in which the biannual energy consumption is matched with the degree-days for that same period in accordance to the three different base temperatures used in this research.

TABLE 1. ENERGY CONSUMPTION AND DEGREE-DAYS FOR BUILDING 6

\begin{tabular}{lllll}
\hline Months & Energy, kWh & $\begin{array}{l}\text { Temp. } \mathbf{~ 1 5}^{\circ} \mathbf{C}, \\
\text { Degree-Day }\end{array}$ & $\begin{array}{l}\text { Temp. Balance, } \\
\text { Degree-Day }\end{array}$ & $\begin{array}{l}\text { Temp. Thermostat, } \\
\text { Degree-Day }\end{array}$ \\
\hline July/Aug & 149.44 & 0 & 0 & 26 \\
Sept/Oct & 233.61 & 37 & 69.5 & 171 \\
Nov/Dec & 2138.91 & 246.5 & 410.5 & 532 \\
Jan/Feb & 1660 & 390.5 & 552 & 684 \\
Mar/April & 849.02 & 230 & 322 & 507.5 \\
May/June & 648.88 & 81.5 & 118 & 324 \\
\hline
\end{tabular}

Following Table 1, energy consumption is plotted against the degree-days for each base temperature case and the coefficient of determination, $R^{2}$, is calculated by fitting a straight line to the data points, as shown in Fig. 2. For each property, the coefficient of determination was calculated following this approach for each of the three base temperature cases.

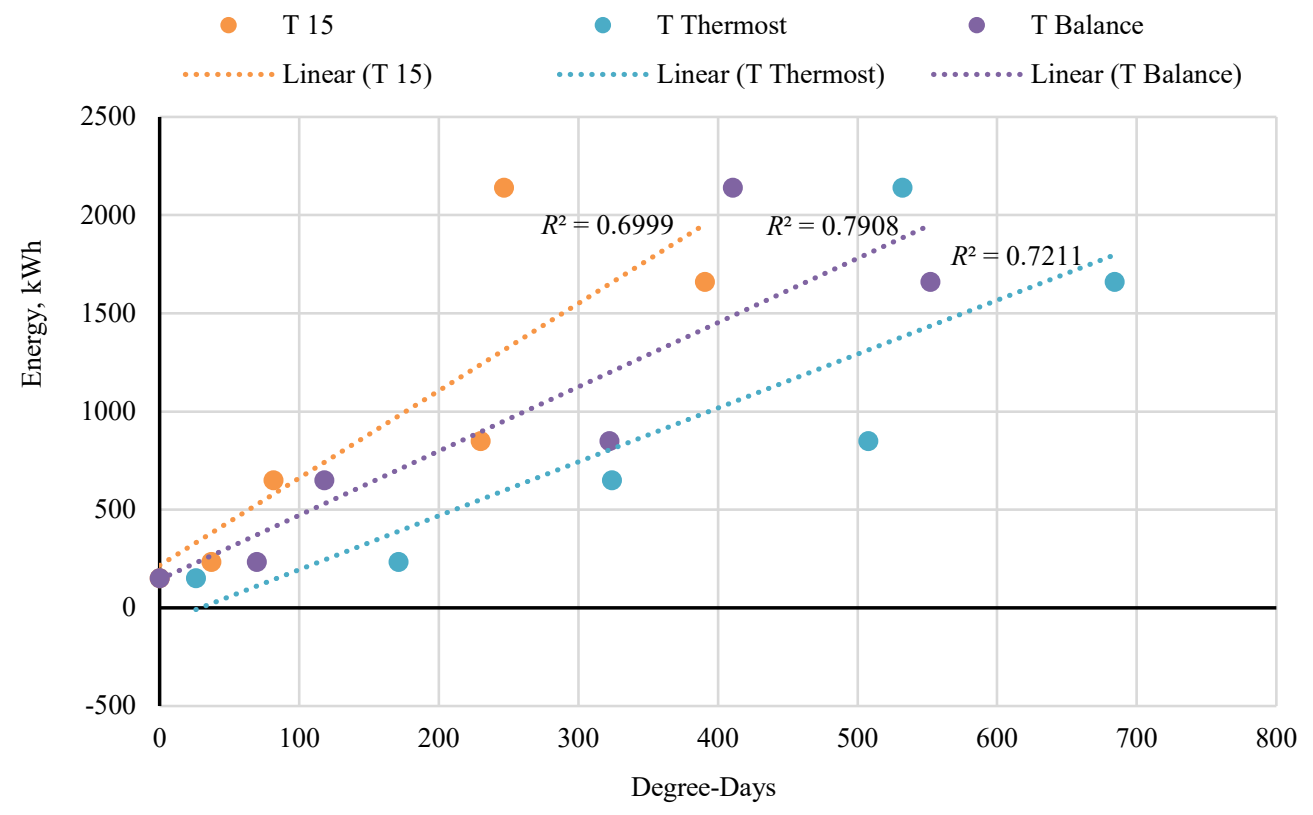

Fig. 2. Energy consumption versus degree-days for building 6. 
The results presented in Table 2 and Fig. 3 show that all three base temperatures are able to correlate energy consumption versus degree-day to a good level of fitness, ranging from 0.5175 to 0.9921 . In nine of the properties, the higher coefficient of determination is reach by using the base temperature of $15^{\circ} \mathrm{C}$, while using the balance temperature as base temperature, provides the best correlation in eight of the properties. Using the thermostat setting as base temperature, only reach the best correlation in three of the properties.

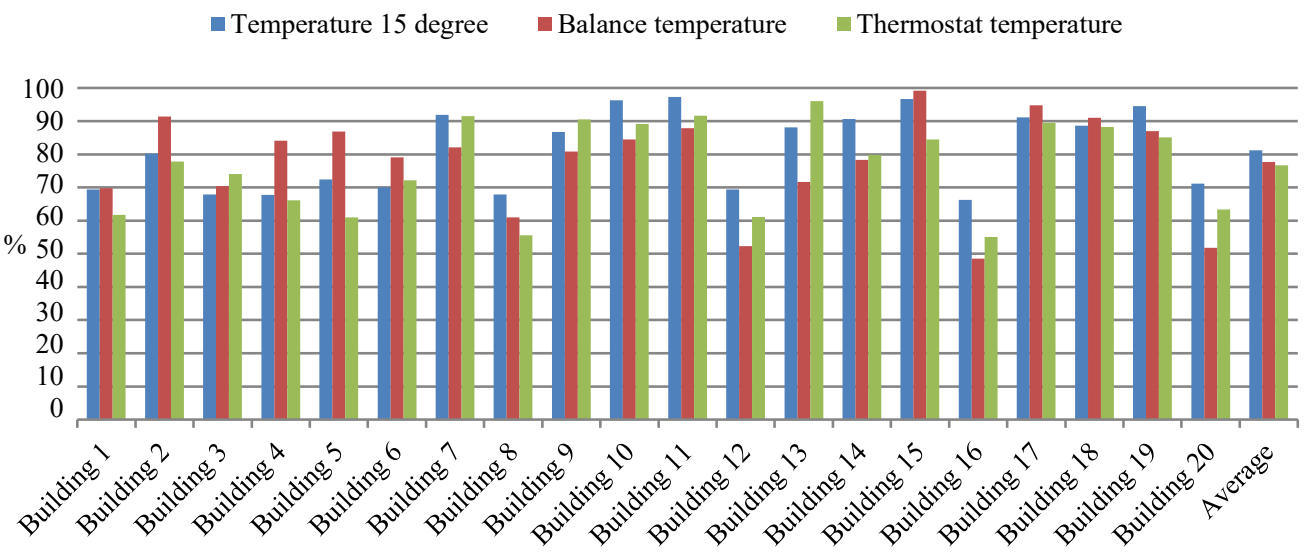

Fig. 3. Coefficient of determination for all buildings and each base temperature.

Most of the calculation for the coefficient of determination for each property, presents a small difference between the degree-day's calculation methods with mostly standard deviation below 0.05 in the comparison of base temperature methods. The standard deviation can provide a good estimation of the agreement between degree-days calculations to explain the energy consumption of the properties.

In general terms and compiling all the properties together as an average, using the base temperature of 15 degrees centigrade generates an average coefficient of determination of 0.8122 with a standard deviation of 0.1189 . In the case of using the balance temperature of the properties as base temperature, the average coefficient of determination of 0.7763 with a standard deviation of 0.1472 . Finally, the use of the thermostat setting as base temperature generates an average coefficient of determination of 0.7669 with a standard deviation of 0.1366 .

Table 3 shows the coefficient of determination, $R^{2}$, as an average and standard deviation for all the properties together and then subdivided by construction date and by size of the properties. It must be noted that in the case of properties prior to 1981, in the case of construction date, only one property was available. In a similar way, in the case of properties of less than $70 \mathrm{~m}^{2}$, for property size, only one property was available. Most of the properties in this research were constructed between 1981 and 2007 and with a size between $70 \mathrm{~m}^{2}$ and $120 \mathrm{~m}^{2}$. This group contained 16 properties and 15 properties respectively of the total cohort of 20 properties.

Taking into consideration the breakdown of properties according to construction date, the bigger cohort with 16 properties, between 1981 and 2007, provides a better correlation for all three based temperatures than when all the properties are considered together. On the opposite, the other two groups, prior 1981 and post 2007, have the coefficient of performance reduce in comparison to all properties together. 
When considering the size of properties, the bigger group with 15 properties, accounting for between $70 \mathrm{~m}^{2}$ and $120 \mathrm{~m}^{2}$, generate higher correlation for the base temperature of 15 degree centigrade and the balance temperature, while the thermostat temperature correlation is slightly reduced. In the case of properties bigger than $120 \mathrm{~m}^{2}$, the correlation is stronger for the base temperature of $15^{\circ} \mathrm{C}$ and the balance temperature, while the thermostat temperature correlation is again reduced. For the property of less than $70 \mathrm{~m}^{2}$, all correlations are weaker although it must be considered that this group is formed of only one property.

TABle 2. DETAILS AND COEFFICIENT OF DETERMINATION $R^{2}$ FOR EACH BUILDING ACCORDING TO DEGREE-DAY CALCULATION

\begin{tabular}{lllllll}
\hline Building & $\begin{array}{l}\text { Type of } \\
\text { Building }\end{array}$ & $\begin{array}{l}\text { Construction } \\
\text { Date }\end{array}$ & $\begin{array}{l}\text { Treated Floor } \\
\text { Area, } \mathbf{~ m}^{\mathbf{2}}\end{array}$ & $\begin{array}{l}\text { Temp. } \\
\mathbf{1 5}^{\circ} \mathbf{C}, \boldsymbol{R}^{\mathbf{2}}\end{array}$ & $\begin{array}{l}\text { Temp. } \\
\text { Balance, } \boldsymbol{R}^{\mathbf{2}}\end{array}$ & $\begin{array}{l}\text { Temp. } \\
\text { Thermostat, } \boldsymbol{R}^{\mathbf{2}}\end{array}$ \\
\hline Building 1 & Owner & $1981-2007$ & 84 & 0.6943 & 0.6976 & 0.6175 \\
Building 2 & Owner & $1981-2007$ & 74 & 0.8019 & 0.9143 & 0.7784 \\
Building 3 & Owner & $1981-2007$ & 135 & 0.6791 & 0.7036 & 0.7398 \\
Building 4 & Owner & After 2007 & 80 & 0.6776 & 0.8412 & 0.6609 \\
Building 5 & Owner & $1981-2007$ & 90 & 0.7236 & 0.8683 & 0.6096 \\
Building 6 & Rented & Prior 1981 & 142 & 0.6999 & 0.7908 & 0.7211 \\
Building 7 & Owner & $1981-2007$ & 85 & 0.9195 & 0.8210 & 0.9145 \\
Building 8 & Owner & $1981-2007$ & 70 & 0.6791 & 0.6099 & 0.5560 \\
Building 9 & Owner & $1981-2007$ & 85 & 0.8673 & 0.8088 & 0.9046 \\
Building 10 & Rented & $1981-2007$ & 80 & 0.9629 & 0.8447 & 0.8915 \\
Building 11 & Owner & $1981-2007$ & 105 & 0.9735 & 0.8790 & 0.9167 \\
Building 12 & Owner & $1981-2007$ & 77 & 0.6938 & 0.5228 & 0.6107 \\
Building 13 & Rented & $1981-2007$ & 160 & 0.8813 & 0.7162 & 0.9598 \\
Building 14 & Social & $1981-2007$ & 97 & 0.9063 & 0.7836 & 0.7986 \\
Building 15 & Owner & $1981-2007$ & 73 & 0.9671 & 0.9921 & 0.8441 \\
Building 16 & Owner & After 2007 & 83 & 0.6630 & 0.4858 & 0.5506 \\
Building 17 & Owner & $1981-2007$ & 120 & 0.9117 & 0.9476 & 0.8947 \\
Building 18 & Owner & $1981-2007$ & 92 & 0.8856 & 0.9107 & 0.8830 \\
Building 19 & Owner & $1981-2007$ & 90 & 0.9455 & 0.8700 & 0.8509 \\
Building 20 & Owner & After 2007 & 67 & 0.7109 & 0.5175 & 0.6342 \\
Average & & & & 0.8122 & 0.7763 & 0.7669 \\
SD & & & & 0.1189 & 0.1472 & 0.1366 \\
\hline
\end{tabular}


TABle 3. COMbined CORRElation $R^{2}$ ACCORding to CONSTRUCTION DATE AND Size

\begin{tabular}{|c|c|c|c|c|}
\hline & & Temp. $15^{\circ} \mathrm{C}, R^{2}$ & Temp. Balance, $R^{2}$ & Temp. Thermostat, $R^{2}$ \\
\hline \multirow{2}{*}{ All Buildings } & Average & 0.8122 & 0.7763 & 0.7669 \\
\hline & SD & 0.1189 & 0.1472 & 0.1366 \\
\hline \multicolumn{5}{|l|}{ By Construction Date } \\
\hline \multirow{2}{*}{ Between 1981-2007 } & Average & 0.8433 & 0.8056 & 0.7982 \\
\hline & SD & 0.1125 & 0.1270 & 0.1319 \\
\hline \multirow{2}{*}{ After 2007} & Average & 0.6838 & 0.6148 & 0.6152 \\
\hline & SD & 0.0246 & 0.1967 & 0.0575 \\
\hline Prior 1981 & & 0.6999 & 0.7908 & 0.7211 \\
\hline \multicolumn{5}{|l|}{ By Size } \\
\hline \multirow{2}{*}{$\begin{array}{l}\text { Between } 70 \mathrm{~m}^{2} \text { and } \\
120 \mathrm{~m}^{2}\end{array}$} & Average & 0.8241 & 0.7900 & 0.7592 \\
\hline & SD & 0.1228 & 0.1472 & 0.1413 \\
\hline \multirow{2}{*}{ More than $120 \mathrm{~m}^{2}$} & Average & 0.7930 & 0.7896 & 0.8289 \\
\hline & SD & 0.1205 & 0.1122 & 0.1169 \\
\hline Less than $70 \mathrm{~m}^{2}$ & & 0.7109 & 0.5175 & 0.6342 \\
\hline
\end{tabular}

\section{Discussion}

The aim of this study was to evaluate the effect of different base temperatures and their impact on the correlation between energy consumption and degree-days. The base temperature was selected as the standard $15{ }^{\circ} \mathrm{C}$ for the region [12], the balance temperature calculated with dynamic building simulations and the thermostat temperature as collected by questionnaires [18].

Layberry [9] highlighted the importance of the selection of base temperature in the calculation of degree-days for the normalization of energy consumption, in this study, the results presented in Table 2 and Fig. 3 agreed with this statement, showing that in almost half of the properties the stronger correlations happened with a base temperature of 15 degree centigrade, while the other half occurred with a base temperature equal to the balance temperature, which was calculated according to the total heat losses and total heat gain for each property on a monthly basis. The coefficient of determination, $\mathrm{R}^{2}$, is smaller, showing a weaker correlation for the case of base temperature taken from the thermostat setting. This disagrees with previous research [14], which showed that using the internal temperature as base temperature can provide more accurately correlations. The main different in this study is that the thermostat setting is fixed across the whole period of study, while in the case of internal temperature [14] the temperature was monitored every 20 minutes and the data was daily average, meaning that each day could potentially have different daily temperature to the previous day and still it will be accounted for. This is one of the main limitations on the use of the thermostat setting as base temperature.

Day et al. [11] argue that the base temperature should be calculated separately for each property under analysis. This has been the process followed by this research when using the balance temperature for each property to calculate degree-days. The balance temperature approach used in this research share similar limitations as the study run by Krese et al. [13], while a far longer data capture and data processing must be in place, for the case of using the balance temperature as base temperature, the improvements of correlation are very small, in 
comparison to using the standard $15{ }^{\circ} \mathrm{C}$ base temperature, which does not require any data capture and processing at all.

Looking into the impact of base temperature on the correlation of properties, according to construction date and size, this study showed in Table 3 that the higher correlation will occur when using the standard $15^{\circ} \mathrm{C}$ base temperature for the main cohorts of properties built between 1981 and 2007 and with a size between $70 \mathrm{~m}^{2}$ and $120 \mathrm{~m}^{2}$. The research could not clearly identify the best base temperature for the other groups as they were very small to draw any conclusions.

While the selection of the correct base temperature remains a paramount to avoid mistakes [16], this research shows that using a longer approach by the implementation of a balance temperature as base temperature does not provide an increase on the accuracy of the correlation between energy consumption and degree-days. On the case of using the thermostat setting as base temperature, the results provide a much weaker correlation, suggesting that this approach should be avoid regardless of the easy data collection opportunities.

\section{Conclusion}

This study had highlighted the effect and impact of selecting different base temperatures for the calculation of degree-days and the correlation between energy consumption and degree-days. While the use of the balance temperature as base temperature could generate very good correlation, they were not so dissimilar from using the standard $15{ }^{\circ} \mathrm{C}$ base temperature to justify the amount of extra work required to generate the balance temperature. The use of the thermostat setting as an indication of the base temperature was not as reliable as the other base temperature methods in generating a good correlation to explain the energy consumption on the 20 properties investigated in this study.

\section{REFERENCES}

[1] Hong W-C. Intelligent Energy Demand Forecasting. London: Springer, 2013. https://doi.org/10.1007/978-1-4471$\underline{4968-2}$

[2] Jansson-Boyd C., et al. Complementing retrofit with engagement: exploring energy consumption with social housing tenants. International Journal of Energy Research 2017:41(8):1150-1163. https://doi.org/10.1002/er.3698

[3] Krarti M. Weatherization and energy efficiency improvement for existing homes - an engineering approach. Boca Raton, Florida: CRC Press, 2013.

[4] Chartered Institution of Building Services Engineering. TM41 Degree-days: theory and application. London: CIBSE Publications, 2006.

[5] Mitchell J. M. Degree-days: Heating and Cooling by the Numbers. Weatherwise 1987:40(6):334-336. https://doi.org/10.1080/00431672.1987.9932080

[6] OrtizBeviá M. J., et al. Evolution of heating and cooling degree-days in Spain: Trends and interannual variability. Global and Planetary Change 2012:92-93:236-247. https://doi.org/10.1016/j.gloplacha.2012.05.023

[7] Bhatnagar M., Mathur J., Garg V. Determining base temperature for heating and cooling degree-days for India. Journal of Building Engineering 2018:18:270-280. https://doi.org/10.1016/j.jobe.2018.03.020

[8] De Rosa M., et al. Heating and cooling building energy demand evaluation; a simplified model and a modified degree days approach. Applied Energy 2014:128:217-229. https://doi.org/10.1016/j.apenergy.2014.04.067

[9] Layberry R. L. Degree-days for building energy management - presentation of a new data set. Building Services Engineering Research and Technology 2008:29(3):273-282. https://doi.org/10.1177/0143624408093886

[10] Layberry R. L. Analysis of errors in degree-days for building energy analysis using Meteorological Office weather station data. Building Services Engineering Research and Technology 2009:30(1):79-86. https://doi.org/10.1177/0143624408098221

[11] Day A. R., et al. Improved methods for evaluating base temperature for use in building energy performance lines. Building Services Engineering Research and Technology 2003:24(4):221-228. https://doi.org/10.1191/0143624403bt073oa 
[12] Instituto para la Diversificacion y Ahorro de la Energia (IDEA). Guía técnica de condiciones climáticas exteriores de Proyecto. Ministerio de Industria, Turismo y Comercio. Gobierno de Espana 2010. (Technical guide of external climatic conditions of the Project. Ministry of Industry, Tourism and Commerce. Government of Spain. 2010.) (in Spanish)

[13] Krese G., Prek M., Butala V. Analysis of Building Electric Energy Consumption Data Using an Improved Cooling Degree Day Method. Journal of Mechanical Engineering 2012:58(2):107-114. https://doi.org/10.5545/svime.2011.160

[14] Jimenez-Bescos C. Assessing the Impact of Degree Day Base Temperatures on The Development of an Energy Index to Measure Energy Reduction. Proceedings of the International Conference for Sustainable Design of the Built Environment 2017:241-246.

[15] Walsh P. J., Miller A. J. The relation between degree-days and base temperature. Applied Energy 1983:13(4):241253. https://doi.org/10.1016/0306-2619(83)90017-X

[16] Woods J., Fuller C. Estimating base temperatures in econometric models that include degree-days. Energy Economics 2014:45:166-171. https://doi.org/10.1016/j.eneco.2014.06.006

[17] D'Amico A., et al. Building energy demand assessment through heating degree days: The importance of a climatic dataset. Applied Energy 2019:242:1285-1306. https://doi.org/10.1016/j.apenergy.2019.03.167

[18] Jimenez-Bescos C., Oregi X. Implementing User Behaviour on Dynamic Building Simulations for Energy Consumption. Environmental and Climate Technologies 2019:23(3):308-318. https://doi.org/10.2478/rtuect-20190097

[19] Designbuilder software [Online]. [Accessed 16.02.2020]. Available: http://www.designbuilding.com

[20] Weather Underground [Online]. [Accessed 16.02.2020]. Available: https://www.wunderground.com/

[21] Bryman A. Social Research Methods. Oxford: Oxford University press, 2004.

[22] Collis J., Hussey R. Business Research. A practical Guide for Undergraduate and Postgraduate Students. London: Palgrave Macmillan, 2003. 